\title{
Epidemiologic Variables Affecting Deaths among COVID-19 Patients in Second Wave of Pandemic in Bundelkhand Region of Uttar Pradesh: A Cross-sectional Study
}

\author{
Suneel Kumar Kaushal', Navin Kumar ${ }^{1}$, Ashok Kumar Patel ${ }^{1,{ }^{*}}$, Mukesh Yadav ${ }^{2}$
}

\section{Suneel Kumar Kaushal', Navin Kumar', Ashok Kumar Patel ${ }^{1{ }^{1 *} \text {, }}$ Mukesh Yadav}

\section{'Department of Community Medicine, Government Allopathic Medical College, Banda, Uttar Pradesh, INDIA. ${ }^{2}$ Government Allopathic Medical College, Banda, Uttar Pradesh, INDIA. \\ Correspondence \\ Dr. Ashok Kumar Patel, \\ Senior Resident, Department of \\ Community Medicine, Government \\ Allopathic Medical College, \\ Banda-210001, Uttar Pradesh, INDIA. \\ Phone no: +91 7348573262 \\ Email: ashoksantosh94@gmail.com \\ History \\ - Submission Date: 16-07-2021 \\ - Revised Date: 08-08-2021 \\ - Accepted Date: 03-09-2021}

DOI : 10.5530/ijmedph.2021.4.38

\section{Article Available online}

http://www.ijmedph.org/v11/i4

\section{Copyright}

(C) 2021 Phcog.Net. This is an openaccess article distributed under the terms of the Creative Commons Attribution 4.0 International license.

\begin{abstract}
Introduction: WHO has declared COVID-19 as a global pandemic on $11^{\text {th }}$ March 2020 . The Corona Virus Disease 2019 (COVID19) has rapidly spread worldwide. First case of COVID-19 was reported on 30 th January 2020 in Kerala state, India. The first COVID-19 case was reported to Government Allopathic medical College Banda on $1^{\text {st }}$ April 2020, and thereafter many COVID-19 cases were admitted and treated. This study was conducted to find the epidemiological variables affection mortality among hospitalised COVID-19 patients. Materials and Methods: Study design: This study was a hospital based cross-sectional study. The outbreak of second wave started and the period was $1^{\text {st }}$ April 2021 to $30^{\text {th }}$ June 2021. Socio-demographic data, clinical signs and symptoms present, history of co-morbidities and vaccination history etc. were taken at the time of admission. Adjusted odds ratio with a 95\% confidence interval was estimated for all the potential covariates associated with death. The p-value less than 0.05 considered statistically significant. Results: Maximum number of cases was found in the age group of 41-60 years (463) followed by 21-40 year age group (379). Out of 1226 cases, 795 $(64.8 \%)$ cases were males respectively. The covariates marital status, sore throat, breathlessness and vaccination status were found to be significantly associated with mortality. Conclusion: Breathlessness, cough, sore throat and fever were the important clinical findings of this study. Also comorbidity was one of the significant risk factors. The COVID death can be minimized by vaccination; therefore there is a need of awareness and health education about COVID vaccine in community.

Key words: COVID-19, Death, Vaccine, Epidemiology, Uttar Pradesh.
\end{abstract}

\section{INTRODUCTION}

The Corona Virus Disease 2019 (COVID19) has rapidly spread worldwide from its place of origin in $\mathrm{Wu}$ han City of China. ${ }^{1}$ COVID-19 pandemic, caused by the severe acute respiratory syndrome corona virus 2 (SARS-CoV-2), has led to over 179.5 million cases across the world and more than 3.88 million deaths $(2.16 \%)$ have been reported at the global level till June 2021. ${ }^{2}$ It was initially named as 2019 novel corona virus, later on updated as SARS-CoV-2 and the name of the disease as Corona Virus Disease 2019 (COVID-19). ${ }^{3}$

WHO has declared COVID-19 as a global pandemic on $11^{\text {th }}$ March $2020 .^{4}$ First case of COVID-19 was reported on $30^{\text {th }}$ January 2020 in Kerala state, India had travel history of Wuhan city. ${ }^{5}$ Till $30^{\text {th }}$ June 2021, a total of 30410768 cases and 3,99,489 deaths have been reported from almost all States and Union Territories of India. Total COVID - 19 cases and deaths reported from Uttar Pradesh till $30^{\text {th }}$ June was $17,06,107$ and 22,591 respectively. ${ }^{6}$

The first COVID-19 case was reported to Government Allopathic medical College Banda on $1^{\text {st }}$ April 2020, and thereafter many COVID-19 cases were admitted and treated. Initially infected persons have manifested with mild symptoms not requiring hospitalization. Second wave of COVID-19 pandemic arrived in the first week of April 2021. A significant proportion of the patients have an illness of moderate to severe nature requiring immediate critical care. Less than fifty percent of the deaths were in elderly population with co morbid conditions.

Patients of higher age and with pre-existing chronic health conditions are at an increased risk of fatal disease outcome. However, detailed information on causes of death and the contribution of pre-existing health conditions to death yet is missing. Several co morbidities, such as hypertension, ischemic heart disease, and obesity were present in the vast majority of patients. Our findings reveal that causes of death were directly related to COVID-19 in the majority of decedents, while they appear not to be an immediate result of pre-existing health conditions and co morbidities. ${ }^{7}$

Government of India had started vaccination from $16^{\text {th }}$ January 2021. Initially it was only for health care workers and front line workers. Later on vaccine was
Cite this article : Kaushal SK, Kumar N, Patel AK, Yadav M. Epidemiologic Variables Affecting Deaths among COVID-19 Patients in Second Wave of Pandemic in Bundelkhand Region of Uttar Pradesh: A Cross-sectional Study. Int J Med Public Health. 2021;11(4):202-5. 
made available for general population more than 18 years of age. Till $30^{\text {th }}$ June 2021 in Uttar Pradesh, 31281449 doses of COVID-19 vaccine has been administered. ${ }^{6}$

\section{Objectives}

(1) To find the epidemiological variables affection mortality among hospitalised COVID-19 patients.

\section{MATERIALS AND METHODS}

Study design: This study was a hospital based cross-sectional study of epidemiological features of COVID19positive patients who were admitted at a tertiary care hospital, Banda, Bundelkhand region of Uttar Pradesh.

Study duration: The outbreak of second wave started and the period was $1^{\text {st }}$ April 2021 to $30^{\text {th }}$ June 2021. Government Allopathic Medical College has been designated for isolation/HDU/ICU and management of COVID-19 positive cases as a dedicated COVID hospital by the State Health Department.

Case definitions: All admitted patients with severe acute respiratory illness (fever, cough, sore throat, and breathlessness); all asymptomatic patients directly and high-risk contacts of a confirmed case tested positive swab report.

Confirmed Covid-19 Cases: Positive test by RT-PCR for testing of COVID19, irrespective of clinical signs and symptoms were considered as confirmed COVID-19 cases.

Inclusion criteria: All confirmed cases were eligible for inclusion in this study.

Data Collection: Patients, who were found to be COVID-19 positive based on the clinical signs and symptoms or satisfying any of the conditions for the case definition as mentioned above, were admitted in isolation/HDU/ICU on his/her situation at L3 hospital. COVID-19 symptoms were clinically confirmed by the attending consultant, and their comorbidities were assessed based on previous history. Nasopharyngeal swab samples were collected by a trained team. Once patients were confirmed as COVID19 positive by the RTPCR, they were shifted to isolation ward for further clinical management.

The epidemiological data were collected through a personal interview with a predesigned Performa at the time of admission. The BHT were filled by Junior Residents on duty that included items such as sociodemographic data, clinical signs and symptoms present at the time of admission, history of co-morbidities such as Diabetes Mellitus, Hypertension, Chronic Lung Disease, Liver diseases, CVD, COPD, and vaccination etc. The data on the outcome; discharge and death of the patient was obtained from the Medical Record Department (MRD) of the hospital. The data collected were compiled on Ms-Excel for the period from $1^{\text {st }}$ April 2021 to $3130^{\text {th }}$ June 2021.

Statistical analysis: The collected data were entered into an Ms- Excel sheet. All analyses were performed using trail version of SPSS 20. Age was categorized into four categories with equal intervals. Logistic regression analysis was performed using death as an outcome variables. Crude odds ratio and adjusted odds ratio with a 95\% confidence interval was estimated for all the potential covariates associated with death. The $p$-value less than 0.05 considered statistically significant.

Ethical consideration: Ethical approval was taken from institutional ethical committee.

\section{RESULTS}

A total of 1226 individuals with confirmed RT-PCR report were admitted and given treatment at the hospital. 742 individuals were discharged while 382 deceased. Table 1 shows the association of socio-demographic characteristics with death as an outcome. Out of 1226 cases, 795 (64.8\%) and $431(35.1 \%)$ cases were males and females respectively. Maximum number of cases was found in the age group of 41-60 years (463) followed by 21-40 year age group (379), > 60 years (344) and $<20$ years (39). The incidence of age-wise case-fatality rate (CFR) showed an increasing trend with an increase in age. The odds of case fatality is showing an increasing trend with increasing age when crude odds ratio for mortality in each age group was computed taking the rest of the other groups as reference. This data shows that the risk of mortality was lower in younger age group. The odds of mortality were lesser in males as compared to females $\{C O R=0.988(0.761-1.283), p$ value $=0.949\}$. In this study 1124 individual were married while 102 were not. Number of deaths among married individuals was 377 while unmarried death was 5 and it shows significant association $\{C O R=9.791(3.952-24.259), p$ value $<0.001\}$. 1164 individuals were Hindus while 62 were from other religions. The association of mortality was not significant for religion ( $p$ value $=0.075$ ).

Table 2 shows the co morbidities and symptoms of COVID patients at the time of admission and their relation to mortality. On admission $162(13.2 \%)$ patients had reported with one or more co morbidities, and $1064(86.8 \%)$ of them had no co morbidities. The most common co-morbidity was Diabetes mellitus 90 (7.3\%) followed by Hypertension 73 (5.9\%), Chronic Lung Disease 76 (6.1\%) and others 32 (2.6\%). Others included hypo-thyroid, cancer of any type, cardiac diseases etc. Out of 382 patients who died due to COVID-19, co morbidity was one of the significant risk factors for death $\{\mathrm{COR}=1.946,95 \% \mathrm{CI}(1.370-2.63)$, p-value $<0.001$ \}. Morbid conditions such as Diabetes Mellitus \{Crude $\mathrm{OR}=1.601,95 \% \mathrm{CI}(1.009-2.536), p$ value $=0.044\}$, hypertension (Crude OR1.686, 95\% CI (1.015-2.798) $p=0.037)$, and Chronic Lung Disease $\{$ Crude OR=1.662, 95\%CI $(1.009-2.733), p$ value $=0.040\}$ were found to be significantly associated with mortality.

Table 2 also shows the distribution of symptoms at the time of admission. On admission, the most common symptom was breathlessness 579 (47.2\%) followed by cough 465 (37.9\%), fever 436 (35.5\%), malaise 65 (5.3\%), others $54(4.4 \%)$, sore throat $49(3.9 \%)$ and headache $17(1.4 \%)$. In other category loss of taste, gastrointestinal symptoms, nausea and vomiting, weakness chest pain, loss of appetite and difficulty in urination were included. 328 (267\%) individuals were asymptomatic out of 1226 . Most of the cases presented with more than one symptom. Breathlessness $\{$ Crude OR $=2.776,95 \%$ CI $(2.060-3.567), p$ value $<0.001\}$ and sore throat $\{$ Crude $\mathrm{OR}=1.849,95 \%$ CI $(1.001-3.410)$, $p$ value $=0.040\}$ were found to be significantly associated with mortality. However except breathlessness and sore throat, none of the symptoms were found to be significantly associated with mortality. This study shows that vaccination has a protective effect against COVID $\{$ Crude OR $=0.613,95 \%$ CI ( 0.401 $0.933)$, $p$ value $=0.018\}$.

Table 3 shows the Logistic Regression analysis of possible risk factors of mortality taking death as the dependent variable. In bivariate analysis; age, marital status, diabetes mellitus, hypertension, chronic lung disease, breathlessness and sore throat were found to be significantly associated with mortality. The covariates marital status, sore throat, breathlessness and vaccination status were found to be significantly associated with mortality.

\section{DISCUSSION}

The present study shows the epidemiological and clinical characteristics of COVID-19 patients admitted in the tertiary care hospital during the period $1^{\text {st }}$ April 2021 to $30^{\text {th }}$ June 2021. A sharp increase in COVID cases was observed in the second wave of COVID-19. The place and time distribution of COVID-19 cases admitted in the hospital from different 


\begin{tabular}{|c|c|c|c|c|c|}
\hline Characteristics & \multicolumn{3}{|c|}{ Death } & \multirow[t]{2}{*}{ COR $(95 \% \mathrm{Cl})$} & \multirow[t]{2}{*}{$P$-value } \\
\hline $\begin{array}{l}\text { Age Group } \\
\text { (in yr) }\end{array}$ & $\begin{array}{c}\text { Yes } \\
\text { n (\%) }\end{array}$ & $\begin{array}{c}\text { No } \\
\text { n (\%) }\end{array}$ & $\begin{array}{l}\text { Total } \\
\text { N (\%) }\end{array}$ & & \\
\hline$\leq 20$ & $2(5.1)$ & 37 (94.9) & $39(100)$ & $\begin{array}{c}0.266 \\
(0.03-1.132)\end{array}$ & 0.073 \\
\hline $21-40$ & 64 (16.9) & $315(83.1)$ & $379(100)$ & $\begin{array}{c}0.101 \\
(0.024-0.426)\end{array}$ & 0.002 \\
\hline $41-60$ & $161(34.8)$ & $302(65.2)$ & $463(100)$ & $\begin{array}{c}0.066 \\
(0.016-0.278)\end{array}$ & 0.000 \\
\hline$>60$ & $155(45.1)$ & $189(54.9)$ & $344(100)$ & Ref & \\
\hline \multicolumn{6}{|l|}{ Gender } \\
\hline Male & $247(31.1)$ & $548(68.9)$ & $795(100)$ & $\begin{array}{c}0.988 \\
(0.761-1.283)\end{array}$ & 0.949 \\
\hline Female & $135(31.3)$ & $296(68.7)$ & $431(100)$ & Ref & \\
\hline \multicolumn{6}{|l|}{ Marital } \\
\hline Married & $377(33.5)$ & $747(66.5)$ & $\begin{array}{l}1124 \\
(100)\end{array}$ & $\begin{array}{c}9.791 \\
(3.952-24.259)\end{array}$ & $<0.001$ \\
\hline $\begin{array}{l}\text { Unmarried } \\
\text { Religion }\end{array}$ & $5(4.9)$ & $97(95.1)$ & $102(100)$ & Ref & \\
\hline Hindu & $369(31.7)$ & $795(68.3)$ & $\begin{array}{l}1164 \\
(100)\end{array}$ & $\begin{array}{c}1.749 \\
(0.938-3.265)\end{array}$ & 0.075 \\
\hline Others & $13(21.0)$ & $49(79.0)$ & $62(100)$ & Ref & \\
\hline$\leq 20$ & $2(5.1)$ & 37 (94.9) & $39(100)$ & $\begin{array}{c}0.266 \\
(0.03-1.132)\end{array}$ & 0.073 \\
\hline $21-40$ & $64(16.9)$ & $315(83.1)$ & $379(100)$ & $\begin{array}{c}0.101 \\
(0.024-0.426)\end{array}$ & 0.002 \\
\hline $41-60$ & $161(34.8)$ & $302(65.2)$ & $463(100)$ & $\begin{array}{c}0.066 \\
(0.016-0.278)\end{array}$ & 0.000 \\
\hline$>60$ & $155(45.1)$ & $189(54.9)$ & $344(100)$ & Ref & \\
\hline
\end{tabular}

districts showed almost a different pattern as observed in the first wave of COVID $19 .^{8}$

A high proportion of males, almost two times of females were observed in this study. A similar finding has also been reported from other studies. ${ }^{9,10}$ This might be due to more outdoor activities of males. In the second wave of COVID-19 pandemic we found that $37.5 \%$ of the patients were in the age group of 41-60 years followed by 21-40 year age group $(30.9 \%)$. We found that people in adult age are more affected than younger age which indicates a higher risk of getting exposure in adult over 40 years of age. In our study married people were more prone to getting COVID-19 infection and death.

The most common symptom observed was breathlessness followed by cough, fever and sore throat. These findings were similar to the other studies reporting breathlessness the most common symptoms. ${ }^{11,12}$ At the time of admission breathlessness and sore throat were found to be significantly associated with case fatality. In this study, $47.2 \%$ of cases had symptoms of breathlessness which was almost similar to a previous study conducted in Pune. ${ }^{13}$ Breathlessness, cough, fever and sore throat were reported as the most common symptoms also seen in previous studies. ${ }^{14,15}$ The clinical features might be because the majority of the patients came with serious signs and symptoms to the dedicated L3 COVID hospital. The case fatality rate among the admitted patients was
Table 2: Co-morbidities, Symptoms and Vaccination status of COVID-19 patients and their relation with mortality.

$\begin{array}{llll}\text { Characteristics } & \text { Death } & \text { COR }(95 \% \mathrm{Cl}) \quad P \text {-value } \\ \text { COMORBIDITIES } & \text { Yes (\%) } & \text { No (\%) } & \text { Total }(\%)\end{array}$

Present

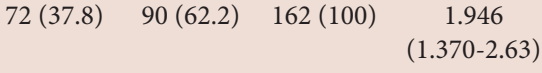

Absent $310(30.3) \quad 754(69.7) \quad 1064(100) \quad$ Ref

Diabetes

Present

$37(41.1) \quad 53(58.9) \quad 90(100) \quad 1.601$ (1.009-2.536)

Absent

$345(30.4) \quad 791(69.6) \quad 1136(100) \quad$ Ref

Hypertension

Present

Absent

$31(42.5) \quad 42(57.5) \quad 73(100) \quad 1.686$

0.037

Chronic Lung

Disease

Present

Absent

Other diseases

Present

Absent

SYMPTOMS

Present

Absent

Fever

Present

Absent

Cough

Present

Absent

Sore Throat

Present

Absent

$351(30.4) \quad 802(69.5) \quad 1153(100) \quad$ Ref

$32(42.1)$

$44(57.9) \quad 76(100)$

1.662

0.040

$350(30.4) \quad 800(69.6) \quad 1150(100) \quad$ Ref

$2(37.5)$

1.336

0.442

$370(31.0) \quad 824(69.0) \quad 1194(100) \quad$ Ref

(1)

$284(31.6) \quad 614(68.4) \quad 898(100) \quad 1.086$ (0.817-1.443)

$98(29.9) \quad 230(70.1) \quad 328(100) \quad$ Ref

$\begin{array}{lllll}1(27.8) & 315(72.2) & 436(100) & 0.779 & 0.062\end{array}$ (0.597-1.015)

261(33) $529(67) \quad 790(100) \quad$ Ref

$150(32.2) \quad 315(67.7) \quad 465(100) \quad 1.086 \quad 0.526$ (0.840-1.403)

$232(30.5) \quad 529(69.5) \quad 761(100) \quad$ Ref

Breathlessness

Present

$22(44.89) \quad 27(55.10) \quad 49(100) \quad 1.849$ (1.001-3.410)

$360(30.58) \quad 817(69.41) \quad 1177(100) \quad$ Ref

Present

$246(42.5) \quad 333(57.5) \quad 579(100) \quad 2.776 \quad<0.001$

Absent

Malaise

Present

Ref

Absent

$14(21.5)$

$51(78.5)$

$65(100)$

0.589

0.083

Absent

Present

$365(31.8) \quad 783(68.2) \quad 1148(100) \quad$ Ref

$2(11.8)$

$17(100)$

0.

Absent

Others

Present

$380(31.4) \quad 829(68.6) \quad 1209(100) \quad$ Ref

Present

0.763

0.391

Absent

Vaccination

Present

$34(22.7) \quad 116(77.3) \quad 150(100) \quad 0.613 \quad 0.018$

Absent

$348(32.3)-728(67.7)$ 
Kaushal, et al.: Epidemiologic Variables Affecting Deaths among COVID-19 Patients

\begin{tabular}{|c|c|c|}
\hline Risk Factors & Adjusted Odds Ratio(95 \% Cl) & $P$-value \\
\hline Marital status & $3.188(1.148-8.855)$ & 0.026 \\
\hline Sore throat & $1.438(1.017-5.843)$ & 0.046 \\
\hline Breathlessness & $3.631(2.339-5.637)$ & $<0.001$ \\
\hline Vaccination & $0.545(0.347-0.856)$ & 0.008 \\
\hline
\end{tabular}

$31.1 \%$ which was quite higher than national average and the state and Figure of $1.34 \%$ and $1.3 \%$ as of 30 June $2021 .{ }^{16,17}$ During the second wave, most of the cases were admitted directly in HDU/ICU or referred by other hospitals with poor oxygen saturation. This could be the possible reason for the high mortality observed in the hospital. Rapid respiratory failure was one of the major reasons observed among the cases that died. Diabetes was the most common co morbidity followed by chronic lung disease and hypertension. Patients, who died, had one or more co-morbidity. The majority of the death was in the age group $>60$ years followed by 41-60 years of age. In previous studies on COVID-19, it has been established that risk increases with age and co morbidities. Co morbidity was one of the significant risk factors for COVID -19 and death. Similar results were observed in previous studies. ${ }^{13,18}$

Finally the adjusted odds ratio was calculated for possible risk factors by using multiple logistic regression analysis. Factors like breathlessness, sore throat, marital status, and vaccination status were found to have significant association with COVID. ${ }^{11,12}$ The percentage of COVID death was seen more in non-vaccinated patients and it was significantly associated. COVID vaccine has good safety profile and it has minimal adverse effect. ${ }^{19}$ The size of this study is sufficient enough to establish the association of various risk factors with case fatality. This is one of the strengths of this study. One of the limitations of this study is selection bias because patients with serious signs and symptoms come to L3 COVID hospital; hence, it could not be generalized.

\section{CONCLUSION}

Breathlessness, cough, sore throat and fever were the important clinical findings of this study. The mortality rate among the COVID cases admitted in the hospital was significantly higher than the national and state Figures. Also co morbidity was one of the significant risk factors. The COVID death can be minimized by vaccination; therefore there is a need of awareness and health education about COVID vaccine in community.

\section{ACKNOWLEDGEMENT}

The authors acknowledge the help of all the junior residents and other health care workers of the institution who helped in the study.

\section{CONFLICT OF INTEREST}

The authors declare no conflict of interest.

\section{ABBREVIATIONS}

HDU: High Dependency Unit; ICU: Intensive Care Unit; RTPCR: Reverse Transcriptase Polymerase Chain Reaction; CVD: Cardio-vascular disease; COPD: Chronic Obstructive Pulmonary Disease; COR: Crude Odds ratio; CI: Confidence Interval.

\section{REFERENCES}

1. European Centre for Disease Prevention and Control. Outbreak of acute respirator syndrome associated with a novel coronavirus, China: first local transmission in the EU/EEA - third update. Stockholm: European center for disease prevention and control; 2020.

2. https://www.worldometers.info/coronavirus/?fbclid=IwAR35ZFiRZJ8tyBCwaz X2Nk7yJjZOLDQiZSA_MsJAfdK74s8f2a_Dgx4lv. [Last assessed on; july 152021 ].

3. Eurosurveillance EditorialTeam. Author's correction for Euro Surveill. 2020;25(4) Euro Surveill. 2020;25(7). doi: 10.2807/1560-7917.ES.2020.25.7.20200220c. PMID 32098643.

4. Available from: https://www.who.int/director-general/speeches/detail/who-director-general-s-openiremarks-at-the-media-briefing-on-covid-19---11-march-2020 [cited 1/9/2021].

5. Available from:https://www.who.int/docs/default-source/coronaviruse/situationreports/20200130-sitrep-10-ncov.pdf?sfvrsn=d0b2e480_2 [cited 1/9/2021].

6. Available from: https://www.covid19india.org/. [Assessed on June 30, 2021] [cited 1/9/2021]

7. Kansara N, Nandapurkar AB, Maniyar R, Yadav AK. Prediction of mortality by age and multi-morbidities among confirmed COVID-19 patients: secondary analysis of surveillance data in Pune, Maharashtra, India. Indian J Public Health. 2021;65(1):64-6. doi: 10.4103/ijph.IJPH_1096_20, PMID 33753693.

8. Kaushal SK, Kumar N, Yadav M, Patel AK. Modelling of COVID-19 positive cases at tertiary care hospital of Bundelkhand region of Uttar Pradesh using regression models. Int J Community Med Public Health. 2021;8(4):1899-903. doi: 10.18203/2394-6040.ijcmph20211252

9. Gupta N, Agrawal S, Ish P, Mishra S, Gaind R, Usha G, et al. Clinical and epidemiologic profile of the initial COVID-19 patients at a tertiary care centre in India. Monaldi Arch Chest Dis. 2020;90(1). doi: 10.4081/monaldi.2020.1294 PMID 32290644.[PubMed].

10. Mazumder A, Arora M, Bharadiya V, Berry $P$, Agarwal $M$, Behera $P$, et al. SARS-CoV-2 epidemic in India: epidemiological features and in silico analysis of the effect of interventions. F1000Res. 2020:9:315. doi: 10.12688/f1000research.23496.2, PMID 32528664, PMCID PMC7262570.[PubMed].

11. Zhou F Yu T, Du R, Fan G, Liu Y Liu Z, et al. Clinical course and risk factors for mortality of adult inpatients with COVID-19 in Wuhan, China: a retrospective cohort study. Lancet. 2020;395(10229):1054-62. doi: 10.1016/S01406736(20)30566-3, PMID 32171076.

12. Wang D, Hu B, Hu C, Zhu F, Liu X, Zhang J, et al. Clinical characteristics of 138 hospitalized patients with 2019 novel coronavirus-infected pneumonia in Wuhan, China. JAMA. 2020:323(11):1061-9. doi: 10.1001/jama.2020.1585, PMID 32031570.

13. Tambe MP, Parande MA, Tapare VS, Borle PS, Lakde RN, Shelke SC, BJMC COVID Epidemiology group. An epidemiological study of laboratory confirmed COVID-19 cases admitted in a tertiary care hospital of Pune, Maharashtra. Indian J Public Health. 2020;64(Supplement);Suppl:S183-7. doi: 10.4103/ijph. IJPH_522_20, PMID 32496252.[PubMed].

14. Han C, Duan C, Zhang S, Spiegel B, Shi H, Wang W, et al. Digestive symptoms in COVID-19 patients with mild disease severity: clinical presentation, stool viral RNA testing, and outcomes. Am J Gastroenterol. 2020;115(6):916-23. doi: 10.14309/ajg.0000000000000664, PMID 32301761.

15. Tostmann A, Bradley J, Bousema T, Yiek WK, Holwerda M, Bleeker-Rovers C, et al. Strong associations and moderate predictive value of early symptoms for SARS-CoV-2 test positivity among healthcare workers, the Netherlands, March 2020. Euro Surveill. 2020 April;25(16):2000508, doi: 10.2807/1560-7917. ES.2020.25.16.2000508, PMID 32347200, PMCID PMC7189649.

16. Available from: https://www.worldometers.info/coronavirus/country/india/ [cited 1/9/2021][assessed on 9 july 2021].

17. Available from: https://www.covid19india.org/ [cited 1/9/2021] [assessed on 9 july 2021].

18. Garg S, Kim L, Whitaker M, O'Halloran A, Cummings C, Holstein R, et al. Hospitalization rates and characteristics of patients hospitalized with laboratoryconfirmed coronavirus disease 2019 - COVID-NET, 14 states, March 1-30, 2020 MMWR Morb Mortal Wkly Rep. 2020;69(15):458-64. doi: 10.15585/mmwr. mm6915e3, PMID 32298251, PMCID PMC7755063.[PubMed].

19. Kaushal SK, Patel AK, Yadav M, Kumar N. Assessment of adverse event following immunization and its co-relates among COVID-19 vaccine recipient in Bundelkhand region of Uttar Pradesh: A cross-sectional study. Indian J Commun Health. 2021 June 30;33(2):397-400. 